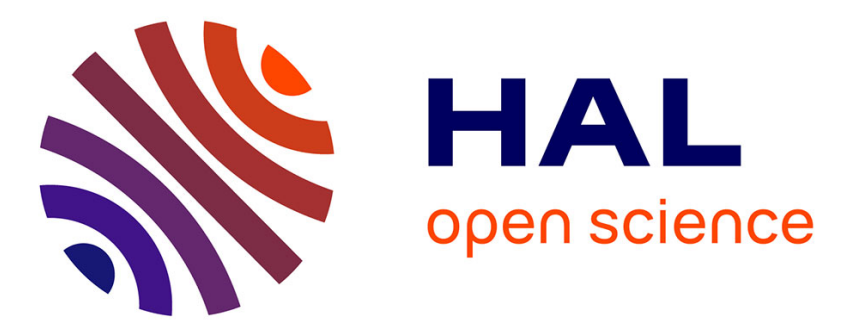

\title{
Lipidomic analysis of Toxoplasma gondii tachyzoites rhoptries: further insights into the role of cholesterol
}

Sébastien Besteiro, Justine Bertrand-Michel, Maryse Lebrun, Henri Vial, Jean-François Dubremetz

\section{To cite this version:}

Sébastien Besteiro, Justine Bertrand-Michel, Maryse Lebrun, Henri Vial, Jean-François Dubremetz. Lipidomic analysis of Toxoplasma gondii tachyzoites rhoptries: further insights into the role of cholesterol. Biochemical Journal, 2008, 415 (1), pp.87-96. 10.1042/BJ20080795 . hal-00479013

\section{HAL Id: hal-00479013 https://hal.science/hal-00479013}

Submitted on 30 Apr 2010

HAL is a multi-disciplinary open access archive for the deposit and dissemination of scientific research documents, whether they are published or not. The documents may come from teaching and research institutions in France or abroad, or from public or private research centers.
L'archive ouverte pluridisciplinaire HAL, est destinée au dépôt et à la diffusion de documents scientifiques de niveau recherche, publiés ou non, émanant des établissements d'enseignement et de recherche français ou étrangers, des laboratoires publics ou privés. 


\title{
Lipidomic analysis of Toxoplasma gondii tachyzoites rhoptries: further insights
} into the role of cholesterol.

Sébastien Besteiro*\#, Justine Bertrand-Michel ${ }^{\star}$, Maryse Lebrun ${ }^{* \dagger}$, Henri Vial* ${ }^{\star}$, JeanFrançois Dubremetz*.

*Laboratoire de Dynamique des Interactions Membranaires Normales et Pathologiques (DIMNP), Universités de Montpellier II et I, Centre National de la Recherche Scientifique (CNRS), UMR 5235, Montpellier, F-34095, France; †INSERM, DIMNP, Montpellier, France; ${ }^{\ddagger}$ INSERM, Institut Claude de Préval, IFR30, Plateau technique de Lipidomique, Toulouse, F-31300, France.

\# to whom correspondence should be addressed (e-mail: sebastien.besteiro@univ-montp2.fr)

Keywords : Toxoplasma, lipidomic, rhoptries, cholesterol, invasion, raft

Short title : Lipidomic analysis of Toxoplasma tachyzoites and their rhoptries

Abbreviations : DPH, 1,6-diphenyl-1,3,5-hexatriene; Chol, cholesterol; PL, phospholipids; SM, sphingomyelins; PE, phosphatidylethanolamine; PC, phosphatidylcholine; PG, phosphatidylglycerol; PS, phosphatidylserine; PI, phosphatidylinositol; LPL, lysophospholipids; CE, cholesteryl esters; DAG diacylglycerides; TAG, triacylglycerides FAME, fatty acid methyl esters; SAFA, saturated fatty acids; UFA, unsaturated fatty acids; CytD, cytochalasin D.

\begin{abstract}
.
Rhoptries are secretory organelles involved in the virulence of the human pathogen Toxoplasma gondii. We have used high performance liquid chromatography and capillary gas-liquid chromatography to isolate and quantify lipids from whole Toxoplasma cells and their purified rhoptries. This comparative lipidomic analysis revealed an enrichment of cholesterol, sphingomyelin and, most of all, saturated fatty acids in the rhoptries. These lipids are known, when present in membranes, to be contributing to their rigidity and, interestingly, fluorescence anisotropy measurements confirmed that rhoptry-derived membranes have a lower fluidity than membranes from whole $T$. gondii cells. Moreover, while rhoptries were initially thought to be highly enriched in cholesterol, we demonstrated it is present in lower proportions and provided additional evidence towards a lack of involvement of rhoptry cholesterol in the process of host cell invasion by the parasite. Indeed, depleting the cholesterol content of the parasites did not prevent the secretion of protein-containing rhoptryderived vesicles and the parasites could still establish a structure called the moving junction, which is necessary for invasion. Instead, the crucial role for host cholesterol for invasion, which has already been demonstrated (Coppens, I. and Joiner, K. A. (2003), Mol.Biol.Cell 14, 3804-3820), might be explained by the need of a cholesterol-rich region of the host cell we could visualise at the point of contact with the attached parasite, in conditions where parasite motility was blocked.
\end{abstract}

\section{Introduction.}

Toxoplasma gondii is a widely spread opportunistic pathogen causing significant diseases in immuno-compromised individuals and neonates. It is an obligate intracellular parasite, able to actively invade virtually all nucleated mammalian cells. As for the other members of the 
phylum Apicomplexa (which also include other important human pathogenic species such as Plasmodium, the causative agent of malaria or Cryptosporidium, responsible for intestinal cryptosporidiosis), the invasion process is mediated by parasite proteins secreted by specialised apical organelles in a coordinated manner [1]. These include micronemal proteins, which are first secreted from small $(\sim 50 \times 250 \mathrm{~nm})$ rod-like micronemes organelles, to allow parasite to adhere to its host cell. A second wave of secretion originates from larger $(\sim 100 \mathrm{X}$ $2500 \mathrm{~nm}$ ) club-shaped compartments called the rhoptries, to form structures such as the moving junction (MJ), at the interface between host cell and parasite plasma membranes, or the parasitophorous vacuole (PV), in which the parasite will grow intra-cellularly.

Proteomic analysis of a rhoptry-enriched fraction from $T$. gondii has recently identified several proteases, phosphatases and kinases that could, once secreted, be involved in the invasion process and the development of the parasites [2]. For instance, T. gondii-specific kinases such as ROP16 and ROP18, which are secreted to the host cell nucleus and the PV membrane (PVM), respectively, have recently been shown to be crucial for proliferation and virulence [3-6]. Rhoptries are thus key players in the invasion process. Their secreted content not only contains proteins, but also includes lipids. Indeed, secreted membrane-bound vesicles originated from the rhoptries can be seen in parasites blocked for invasion by cytochalasin D (CytD, [7]). Membranous structures can also be visualised by electron microscopy inside the organelle [8]. However, the exact role played by rhoptry lipids in invasion or in the pathogenicity in general is unknown. Only a few studies so far have attempted to determine the lipids composition of the rhoptries, by using thin-layer chromatography or enzymatic assays to perform quantitative and qualitative analyses on rhoptry-enriched fractions $[9 ; 10]$. The main conclusion from these studies, was that the rhoptries seemed to be particularly enriched in cholesterol (Chol), with a Chol to phospholipids (PL) ratio >1, although Chol appeared to be non-essential for parasite virulence and host cell invasion [9].

To the contrary, host cell Chol is essential for the entry of Toxoplasma and Chol is found at the PVM shortly after invasion [9]. Several studies have also shown that proteins and lipids contained in Chol-enriched "raft" microdomains on the host cell's plasma membrane are selectively incorporated in the PVM during parasite entry [11;12].

In the present work, we sought to determine the lipid composition of the rhoptries using more sensitive techniques than those used previously. Comparative lipid composition and quantitative analyses of whole cells and rhoptry-enriched fractions were performed by high performance liquid chromatography (HPLC) and capillary gas-liquid chromatography. We found an enrichment of saturated fatty acids in the rhoptries, suggesting an elevated rigidity for membranes derived from these organelles. We also found a lower enrichment of Chol than claimed before for these organelles. The role of rhoptry Chol was further verified by investigations on rhoptry-secreted vesicles during invasion.

\section{Experimental.}

Parasite growth.

Tachyzoites of the RH $\Delta \mathrm{HX}$ strain, deleted for hypoxanthine guanine phosphoribosyl transferase [13], were propagated in vitro under standard procedures, by serial passage in human foreskin fibroblast (HFF) monolayers in Dulbecco's modified Eagle medium (DMEM, Invitrogen) supplemented with $10 \%$ fetal bovine serum. Mass productions of tachyzoites were achieved by infecting monolayers of Vero cells grown in DMEM supplemented with $3 \%$ fetal bovine serum at $37{ }^{\circ} \mathrm{C}$ and under $5 \% \mathrm{CO}_{2}$.

Preparation of cell extracts.

Tachyzoites for lipid analysis were collected by scrapping the cell monolayer, released by passage trough a 22 gauge needle and extracellular parasites were filtered on a $3 \mu \mathrm{m}$ 
polycarbonate membrane (Whatman) to remove host cell debris. The parasites were pelleted at $750 \mathrm{~g}$ for 10 minutes and washed three times in PBS before being immediately frozen at $20^{\circ} \mathrm{C}$ under nitrogen atmosphere. The absence of contamination by cell debris was assessed by treating uninfected Vero host cells similarly and performing a subsequent lipidomic analysis. The amounts of lipids measured from lysed and $3 \mu \mathrm{m}$-filtered Vero cells represented at most about $4 \%$ that of the purified tachyzoites and hence were considered negligible.

\section{Purification of the rhoptry-enriched fraction.}

Rhoptry-enriched fractions were prepared using a protocol adapted from previously published methods [2;14]. Briefly, $\sim 10^{10}$ purified tachyzoites were washed once in phosphate-buffered saline (PBS) buffer and once in homogenisation buffer $(250 \mathrm{mM}$ sucrose, $1 \mathrm{mM}$ EDTA, 10 $\mathrm{mM}$ MOPS $\mathrm{pH} 7.2,2 \mathrm{mM}$ DTT) at $1300 \mathrm{~g}$ for 10 minutes. Parasites were then resuspended at $5.10^{8}$ cells $/ \mathrm{ml}$ in homogenisation buffer and disrupted by passage through a French press at 35 $\mathrm{kg} / \mathrm{cm}^{2}$. Intact cells and large debris were collected by centrifugation at $1300 \mathrm{~g}$ for 5 minutes, resuspended in homogenisation buffer and submitted to a second disruption step with the French press. After a last centrifugation at $1300 \mathrm{~g}$ for 5 minutes, supernatants containing lysed cell contents were pooled. From these supernatants, an organellar fraction was obtained by centrifugation at $15000 \mathrm{~g}$ for 30 minutes. The pellet was resuspended in homogenisation buffer and Percoll was added to a final concentration of $30 \%$. The mix was centrifuged at $66000 \mathrm{~g}$ for 30 minutes in a Beckman Ti-50 rotor. The rhoptry-enriched band was collected near the bottom of the gradient (see Fig. 1A). Percoll was washed out by two successive centrifugations in homogenisation buffer at $100000 \mathrm{~g}$ for 30 minutes. All steps were carried out at $4^{\circ} \mathrm{C}$. Pellets were immediately frozen at $-20^{\circ} \mathrm{C}$ under nitrogen atmosphere.

Purity of the fractions was determined by Western blot and immunofluorescence analysis with antibodies specific for several organellar compartments. Enrichment was calculated by band densitometry measurements using the ImageJ software (National Institute of Health, USA) after normalisation on the total protein concentration.

\section{Determination of protein concentration.}

Protein concentrations were determined by the bicinchoninic acid (BCA) assay (Interchim) or the Bradford protein assay (Bio-Rad) according to the respective protocols supplied by the manufacturers.

\section{Immunoblotting.}

Western blots were performed as described previously [15]. The primary antibodies used and their respective dilutions were mouse monoclonal anti-ROP5 diluted 1:1000 (T5 3E2, [14]), rabbit anti-Hsp28 diluted 1:1000 [16], rabbit anti-GRA3 diluted 1:1000 [17], mouse monoclonal anti-Sag1 diluted 1:500 (T4 1E5, [18]).

\section{Lipid profiling.}

Neutral lipid molecular species analysis by gas-liquid chromatography.

Parasites or rhoptries fractions were homogenised in $2 \mathrm{ml}$ of methanol/ $5 \mathrm{mM}$ EGTA $(2: 1 \mathrm{v} / \mathrm{v})$ with FastPrep homogeniser (MP Biochemicals). $100 \mu \mathrm{l}$ were evaporated, dry pellets were dissolved in $0.25 \mathrm{ml}$ (or $0.05 \mathrm{ml}$ ) of $\mathrm{NaOH}(0.1 \mathrm{M})$ for cells (or rhoptries) overnight and used to determine protein concentration. Lipids corresponding to $0.3 \mathrm{ml}$ of the homogenate were extracted according to Bligh and Dyer [19] in chloroform/methanol/water (2.5:2.5:2.1, v/v/v), in the presence of internal standards: $2 \mu \mathrm{g}$ of stigmasterol, $2 \mu \mathrm{g}$ of 1,3-dimyristine, $2 \mu \mathrm{g}$ of cholesteryl heptadecanoate and $2 \mu \mathrm{g}$ of glyceryl triheptadecanoate. Chloroform phase was evaporated to dryness. Neutral lipids were separated over SPE column (Strata SI-1 Silica 55 
$\mu \mathrm{m}, 70 \AA, 100 \mathrm{mg}$ ): after washing the cartridge with $2 \mathrm{ml}$ of chloroform, the extract was applied on the cartridge in $20 \mu \mathrm{l}$ of chloroform, and neutral lipids were eluted with chloroform ( $2 \mathrm{ml}$ ). The organic phase was evaporated to dryness, and dissolved in $20 \mu \mathrm{l}$ of ethyl acetate. 1 $\mu 1$ of the lipid extract was analyzed by gas-liquid chromatography on a Focus Thermo Electron system using an Zebron-1 fused silica capillary columns ( $5 \mathrm{~m}$ x $0.32 \mathrm{~mm}$ ID, 0.50 $\mu \mathrm{m}$ film thickness, Phenomenex) [20]. Oven temperature was programmed from $200^{\circ} \mathrm{C}$ to $350^{\circ} \mathrm{C}$ at a rate of $5^{\circ} \mathrm{C}$ per minute and the carrier gas was hydrogen $(0.5 \mathrm{bar})$. The injector and the detector were at $315^{\circ} \mathrm{C}$ and $345^{\circ} \mathrm{C}$, respectively.

Ceramide-sphingomyelin analysis.

Lipids corresponding to $0.4 \mathrm{ml}$ of the homogenate were extracted as described above, in the presence of the internal standard ceramide $\mathrm{NC} 15(2 \mu \mathrm{g}$, prepared according to Vieu et al. [21]), the dried lipid extract was submitted to a mild-alkaline treatment in methanolic $\mathrm{NaOH}$ $0.6 \mathrm{~N}(1 \mathrm{ml})$, a second organic extraction and then to silylation in $50 \mu \mathrm{l}$ BSTFA (1\% TMSCl)acetonitrile $(1: 1, \mathrm{v} / \mathrm{v})$ overnight at room temperature. The extract $(5 \mu \mathrm{l})$ was directly analysed by gas-liquid chromatography [21] on a 4890 Hewlett Packard system using a RTX-50 fused silica capillary column ( $30 \mathrm{~m}$ x $0.32 \mathrm{~mm}$ i.d, $0.1 \mu \mathrm{m}$ film thickness, Restek). Oven temperature was programmed from $195^{\circ} \mathrm{C}$ to $310^{\circ} \mathrm{C}\left(12^{\prime}\right)$ at a rate of $3.5^{\circ} \mathrm{C}$ per minute and the carrier gas was hydrogen $(0.5$ bar $)$. The injector and the detector were at $310^{\circ} \mathrm{C}$ and $340^{\circ} \mathrm{C}$ respectively.

Phospholipids analysis.

Lipids corresponding to $1 \mathrm{ml}$ of the homogenate were extracted as described above, but without internal standard. The lipid extract was dissolved in $50 \mu$ l of buffer A (hexane/isopropanol, 82:18, v/v), $10 \mu 1$ to $45 \mu \mathrm{l}$ were analysed by HPLC on a Summit system (Dionex) using an Uptisphere 6OH $(5 \mu \mathrm{m}) 250 \times 2 \mathrm{~mm}$ column (Interchim). The flow rate was $0.25 \mathrm{ml} / \mathrm{minute}$ and the temperature was kept at $25^{\circ} \mathrm{C}$ during all runs. A light-scattering detector was used for the detection (PL-ELS2100, Polymer Laboratories). The evaporator and nebulisator temperatures were kept respectively at 50 and $80^{\circ} \mathrm{C}$, and nitrogen pressure was $1.8 \mathrm{ml} / \mathrm{minute}$. A binary solvent system was used with (A): hexane/isopropanol $(82: 18, \mathrm{v} / \mathrm{v})$ and $(\mathrm{B})$ : isopropanol/water $(85: 15, \mathrm{v} / \mathrm{v})$ in the presence of triethylamine $(0.014 \%, \mathrm{v} / \mathrm{v})$ and acetic acid $(0.5 \%, \mathrm{v} / \mathrm{v})$. The gradient profile was started at $5 \% \mathrm{~B}$ for $5 \mathrm{~min}$, was moved to $35 \% \mathrm{~B}$ after 25 minutes, and then to $85 \% \mathrm{~B}$ after 8 minutes. Finally, the gradient was returned to the starting conditions after 10 minutes and the column was equilibrated for 10 minutes before the next run.

Fatty Acid Methyl Ester (FAME) analysis.

Lipids corresponding to $0.2 \mathrm{ml}$ of the homogenate were extracted as described above, in the presence of the internal standards glyceryl triheptadecanoate $(2 \mu \mathrm{g})$, and transmethylated for 1 $\mathrm{h}$ in boron trifluoride methanol solution $14 \%$ (Sigma, $1 \mathrm{ml}$ ) at $55^{\circ} \mathrm{C}$. After addition of water $(1$ $\mathrm{ml})$, FAMEs were extracted with hexane $(3 \mathrm{ml})$, evaporated to dryness and dissolved in ethyl acetate $(20 \mu \mathrm{l})$. FAME $(1 \mu \mathrm{l})$ were analysed by gas-liquid chromatography [22] on a 5890 Hewlett Packard system using a Famewax fused silica capillary column (30 m X $0.32 \mathrm{~mm}$ ID, $0.25 \mu \mathrm{m}$ film thickness, Restek). Oven temperature was programmed from $110^{\circ} \mathrm{C}$ to $220^{\circ} \mathrm{C}$ at a rate of $2^{\circ} \mathrm{C}$ per minute and the carrier gas was hydrogen $(0.5$ bar $)$. The injector and the detector were at $225^{\circ} \mathrm{C}$ and $245^{\circ} \mathrm{C}$, respectively.

\section{Fluorescence anisotropy.}

Membrane fluidity was evaluated with the fluorescent probe 1,6-diphenyl-1,3,5-hexatriene (DPH) as described by Shinitzky and Barenholz [23]. According to this method, the greater the extent of probe rotation during its excited state lifetime, the smaller will be the observed fluorescence anisotropy $(r)$, to the extent that $r=0$ for complete DPH reorientation.

The DPH fluorescence anisotropy was determined by the formula: $r=\left(\left(I_{\mathrm{VV}}\right)-\mathrm{G}\left(I_{\mathrm{VH}}\right)\right) /(($ 
$\left.I_{\mathrm{VV}}\right)+2 \mathrm{G}\left(I_{\mathrm{VH}}\right)$ ) where $I_{\mathrm{VV}}$ and $I_{\mathrm{VH}}$ are the intensities of the emitted light whose plane of polarisation is oriented, respectively, parallel and perpendicular to the plane of polarisation of the excitation beam. $\mathrm{G}$ is the correction grating factor, $I_{\mathrm{HV}} / I_{\mathrm{HH}}$. The latter is instrumentdependent and accounts for the different sensitivity of photomultipliers to polarised light, measured as the intensities of emitted beams in the vertical $\left(I_{\mathrm{HV}}\right)$ and horizontal $\left(I_{\mathrm{HH}}\right)$ directions when the excitation beam is oriented vertically.

Whole tachyzoites, rhoptries, or erythrocyte "ghosts" (hypotonic "ghosts" prepared according to the protocol described by Blisnick et al. [24]) samples corresponding to $\sim 100 \mu \mathrm{g} / \mathrm{ml}$ of proteins were incubated with $2 \mu \mathrm{M}$ of DPH in PBS at $37^{\circ} \mathrm{C}$ for 30 minutes in the dark, with an optional methyl- $\beta$-cyclodextrin treatment $\left(5 \mathrm{mM}, 30\right.$ minutes at $\left.37^{\circ} \mathrm{C}\right)$ to deplete cholesterol prior to incubation. Membranes were washed once in PBS before measuring the anisotropy. The DPH anisotropy was measured at $25^{\circ} \mathrm{C}$, using a Perkin-Elmer LS-55 spectrophotometer, with the excitation and emission monochromators fixed at 355 and 430 $\mathrm{nm}$, respectively. Excitation and emission slits (band passes) were set at 2.5 and $5.0 \mathrm{~nm}$, respectively. The intensity values for unlabelled samples were subtracted and corrections made for light-scattering artefacts likely to be found in the organellar or cellular suspensions.

Invasion assays, immunofluorescence and filipin labeling.

Invasion assays were carried out by allowing tachyzoites to sediment on confluent HFF for 20 minutes at $4{ }^{\circ} \mathrm{C}$ and subsequently warming them during $2-5 \mathrm{~min}$ at $37^{\circ} \mathrm{C}$ to trigger invasion. An excess volume of $4 \%$ paraformaldehyde in PBS was added both to stop the invasion and fix the cells. When needed, cytochalasin D treatment was applied, by pre-incubating the parasites with $1 \mu \mathrm{M}$ of the drug for 20 minutes before invasion and then allowing them to sediment on $\mathrm{HFF}$ monolayers for 20 minutes at $37^{\circ} \mathrm{C}$, still in the presence of drug. Extracellular parasites were washed and cells were fixed with $4 \%$ paraformaldehyde in PBS. Immunofluorescence assays were performed as follows. After fixation, cells were blocked in PBS containing $0.1 \% \mathrm{w} / \mathrm{v}$ bovine serum albumin (BSA) for 15 minutes, before incubation with the primary antibody for 1 hour in PBS-BSA. Primary antibodies used were mouse monoclonal anti-RON4 antibody (T5 4H1, [14]) diluted at 1:1000 and rabbit anti-ROP1 antibody (J.F. Dubremetz and O. Mercereau-Puijalon, unpublished) at 1:1000. For organelle detection in fraction III, mouse monoclonal anti-ROP2,3,4 (T3 4A7, [25]) and rabbit antiGRA3 [17] were used at 1:1000. After three PBS washes and another blocking step in PBSBSA, the cells were then incubated with the respective alexa 488- or alexa 594-coupled antirabbit or anti- mouse secondary antibodies (Invitrogen) at the dilution recommended by the supplier.

For the fluorescent labelling of membrane cholesterol, filipin $(10 \mathrm{mg} / \mathrm{ml}$ in dimethyl sulfoxide, Sigma) was used at $50 \mu \mathrm{g} / \mathrm{ml}$ on fixed cells, in addition to the primary and secondary antibodies.

Slides were mounted with Immumount (Calbiochem) and observed with a Leica DMRA2 microscope. Images were acquired with a Micromax YHS 1300 camera (Princeton Instruments) using the Metamorph software (Molecular Devices); image acquisition was performed on workstations of the Montpellier RIO Imaging facility.

Cholesterol-depletion of $\mathrm{T}$. gondii tachyzoites.

Cholesterol-depleted tachyzoites were obtained as described previously [9]. Tachyzoites were put to invade HFF monolayers, which were subsequently treated with $4 \mu \mathrm{M}$ lovastatin (Sigma, activated as the dihydroxy acid form) and supplemented with $250 \mu \mathrm{M}$ mevalonate (Sigma) in complete DMEM for two days. Before cell lysis, culture medium was replaced by serum-free DMEM and methyl- $\beta$-cyclodextrin (Sigma) was added to a final concentration of $10 \mathrm{mM}$ for 20 minutes. Cells were scrapped and lysed by passage trough a 22 gauge needle to 
free the parasites, which were left in the presence of methyl- $\beta$-cyclodextrin for an extra 25 minutes. Cholesterol depletion was routinely assessed by UV-microscopic observation of filipin-treated parasites. Quantification of cholesterol concentration in the purified tachyzoites obtained after a typical treatment was assessed by gas-liquid chromatography and showed a reduction of $\sim 70 \%$ of parasite cholesterol.

Statistical analysis.

Values were expressed as mean \pm standard error of the mean (SEM). Data were analysed for comparison using unpaired Student's T-test with equal variance (homoscedastic) for different samples or paired Student's T-test for similar samples before and after treatment. A $p$ value of $<0.005$ or $<0.05$ was used as the level of significance.

\section{Results and discussion.}

Preparation of the rhoptry-enriched fraction. Rhoptries-enriched fractions were isolated as previously described $[2 ; 10 ; 14]$. This cell fractionation on a Percoll gradient allowed us to separate the rhoptries from other sub-cellular components, as rhoptries were highly enriched in a distinct band near the bottom of the gradient (Fig. 1A, fraction III). However, this fraction could occasionally be found to be contaminated with other organelles such as mitochondria, or dense granules [2;14]. The protocol used by Bradley et al. for the proteomic analysis of the rhoptries [2], providing an improved purity of the rhoptry fraction by the use of a second fractionation on a sucrose gradient, is leading to an extensive loss of material and could not be implemented for our lipidomic analysis. Instead, we systematically analysed the fractions by Western blot using markers for rhoptries, dense granules, mitochondria and plasma membrane (Fig. 1B). In a typical fraction retained for lipidomic analysis, fraction III was indeed found to be enriched in rhoptry markers, whereas it contained, at most, only traces of mitochondria and plasma membrane components and few contaminating dense granules (Fig. 1B). Quantification of the enrichment of each marker was performed by measuring band densitometry after Western blot analysis (Fig. 1C). All markers were found to be present in fraction I, where they would be trapped in incompletely lysed parasites. In addition, the rhoptry marker ROP5 showed a highly specific, yet moderate, enrichment in fraction III. This 6.6-fold enrichment could be explained by the fact that rhoptries occupy a large part of the total cell volume (10 to $30 \%,[26])$ and are relatively rich in proteins ([2] and this study). Consequently, rhoptry proteins would already be highly represented in total cell extracts. Most importantly, the rhoptry marker showed a more than 20-fold enrichment over the marker from the most commonly contaminating organelle, the dense granules (Fig. 1C). This demonstrates the high purity of the rhoptry-enriched fraction. It was further verified by immuno-detection and microscopic analysis of fraction III using dense granules (anti-GRA3) or rhoptry (anti-ROP2,3,4) -specific antibodies: quantitative analysis of the labelled microscopic objects showed that dense granules would generally represented less than $10 \%$ of the organelles present in fraction III (data not shown). These rhoptry-enriched fractions, as well as purified extracellular tachyzoites from $T$. gondii, were used for qualitative and quantitative lipidomic analyses by HPLC and capillary gas-liquid chromatography.

Phospholipid and ceramides composition. Analysis of the PL class revealed that rhoptries contain about 3.6 times less total phospholipids per mg of proteins than tachyzoites (Fig. 2A) and this was the case for all the PL subclasses. The ratio of the respective PL subclasses to total PL showed some differences between the two extracts (Fig. 2B). One common feature is that phosphatidylcholine, a major structural component of membrane bilayers, which can be both scavenged by Toxoplasma from its host cell or synthesised by the parasite [12], is the main PL found both in rhoptries and whole Toxoplasma extracts (Fig. 2B). On the other hand, 
noticeable differences include the absence of phosphatidylserine, reduced amounts of phosphatidylethanolamine as well as higher amounts of sphingomyelins (SM) and, less consistently, lysoPL and phosphatidylinositol in the rhoptries (Fig. 2A, 2B). These results were globally in accordance with previous studies [10;27]. For both whole cells and rhoptry fractions, ceramides were also separated and quantified together with SM. The main species found were short-chain (C16, C18) sphingolipids, but no qualitative difference between the extracts could be reproducibly observed (data not shown). Among the sphingolipids, SM were consistently found in higher amounts than ceramides (34.9 vs. 5.40 nmoles.mg proteins ${ }^{-1}$, respectively, for whole cells); it was especially the case for the rhoptries (17.88 vs. 1.81 nmoles.mg proteins ${ }^{-1}$, respectively), where the proportion of SM among the other PL was particularly high compared to whole cells (Fig. 2B).

Fatty acids. Toxoplasma is known to be able to synthesise fatty acids de novo thanks to the presence of the fatty acid synthesis (FAS)I and FASII systems, but it is also able to scavenge fatty acids from its host [28]. For the estimation of total fatty acids composition, lipids were extracted from tachyzoites and rhoptry-enriched fractions, to be subsequently analysed as fatty acid methyl esters (FAME). Several of the main FAME species were found in both types of extracts (Table 1): palmitic (C16:0) and stearic (C18:0) acids are the most abundant saturated fatty acids (SAFA) found in tachyzoites or rhoptries; similarly, for both extracts, the most represented unsaturated fatty (UFA) acid is the oleic acid (C18:1 n-9, Table 1). However, important qualitative differences were found. First, the rhoptry extracts were found to lack several long chain fatty acids (Table 1). Also, one striking difference was that rhoptry fractions contained high proportions of SAFA compared with the mono- and poly-UFA species (Fig. 3). Indeed, our results for tachyzoites extracts show a SAFA/UFA ratio of $\sim 0.9$ (Table 3), in accordance with previously published results [29] describing a rich content of UFA in Toxoplasma cells, whereas in rhoptries we found a SAFA/UFA ratio of 2.24 (Table 3). This is of importance as fatty acid composition is known to be involved, along with Chol, in the regulation of the fluidity of the membranes [30] and this will be discussed later.

Neutral lipids. Qualitative and quantitative analysis of neutral lipids (NL) were also performed on tachyzoites and rhoptry-enriched fractions. Here, no qualitative difference was observed, both extracts were found to contain the same types of cholesteryl esters (CE), diacylglycerides (DAG) and triacylglycerides (TAG) (Table 2). CE can be synthesised from Chol by Toxoplasma and although it was previously suggested that palmitate could to be preferentially used to esterify Chol in the parasite [31], the main CE species we found in both extracts was a C18 (Table 2).

There were quantitative differences however. Indeed, whole cells bore elevated amounts of TAG compared to DAG, which was not the case in the rhoptry fractions, where both CE and TAG were found in lower proportions (Fig. 4). CE and TAG cannot integrate into the phospholipid bilayer [32] so they cluster to form the hydrophobic core of the so-called lipid bodies. Lipid bodies are stores of NL, which can be used for energy production or membrane biogenesis [33], and those structures are present in Apicomplexa (see [34] for a review). It is thus likely that the elevated levels of TAG found in whole cell extracts reflect the presence of these lipids in the storage organelles where they could be the main constituent.

Previous studies by us [10] and others [9], had reported that rhoptries were Chol-rich organelles, with an unusually high $\mathrm{Chol} / \mathrm{PL}$ ratio $(>1)$. Although we found significant amounts of Chol in the rhoptry-enriched fraction, and a Chol/PL ratio higher than for the whole cells (0.34 vs 0.24 , respectively, Table 3 ) our current results differ from those previous findings. Because of the different methodologies used in past studies to measure the Chol concentrations (enzymatic assay and quantitative thin layer chromatography), we also sought 
to use one of these alternative approaches (a colorimetric assay based on the Chol oxidase) to assess the Chol levels in our tachyzoites and rhoptries samples (Supplementary Table 1). Chol concentrations in both whole cells and Chol-enriched fraction (fraction III) were found to be in the same range as the values that were determined by chromatography (Table 2), confirming that our results were consistent. We have no obvious explanation for the differences observed with previously published results, but the reasons could be multiple; for instance, there could possibly come from experimental changes in the culture conditions, or the slightly modified protocol used for the purification of the organelles.

Rhoptries-derived membranes have a high rigidity compared to whole cell membranes. The fluidity of biological membranes is known to be modulated by their lipidic composition [30;35;36]. The main modulators are i) the Chol concentration: when Chol is present in large amounts, it introduces conformational ordering of the lipid chains and it increases the mechanical stiffness while keeping the membrane fluid ii) the SM concentration: SM have the capacity to form intermolecular hydrogen bonds involving its ceramide constituent with other lipids, which is likely to stabilise and rigidify membranes iii) the degree of unsaturation of the hydrocarbon tail: lipids with unsaturated fatty acids, which have kinks in their acyl chains are more likely to be disordered. These three parameters can be reflected by the following three ratios (the higher they are, the more rigid is the membrane), respectively, Chol/PL, SM/PC and SAFA/UFA. When comparing to membranes from a well studied cell type such as erythrocytes, whole Toxoplasma cells have lower Chol/PL, SM/PC and SAFA/UFA ratios, which could be indicative of a higher membrane fluidity (Table 3) as already described for tachyzoites [29;37]. However, as mentioned before, lipids from rhoptry-enriched fractions display higher Chol/PL, SM/PC and SAFA/UFA ratios than whole tachyzoites (Table 3). When compared to erythrocytes, rhoptry lipids show lower Chol/PL and SM/PC ratios, but on the other hand displayed a much higher SAFA/UFA ratio (Table 3), making it difficult to predict their fluidity.

We thus used the fluorescent lipophilic molecule DPH, which has been established as a probe to measure the fluidity of the lipid bilayer of liposomes, biological membranes and whole cells, by fluorescence anisotropy $(r)$ assay [23]. DPH partitions equally between the different lipid domains in a membrane, without apparent concentration differences between ordered and disordered lipid domains and it is thought to be evenly distributed among all the lipidic regions of a whole living cell. The anisotropy of DPH reflects the capacity of this probe to move in its lipid surroundings and hence, the fluidity of the membranes: the higher the anisotropy value, the higher the rigidity of the membranes. DPH was used on membranes from whole Toxoplasma cells, as well as tachyzoites "ghosts" and rhoptry-enriched fractions from the Percoll gradient (fractions I and III, respectively, Fig. 1); we also used erythrocyte "ghosts" as a control, as they have been extensively studied. Our results show that while membranes from whole Toxoplasma tachyzoites and parasite "ghosts" seemed to have a low DPH anisotropy value $(\sim 0.15$ and 0.17 , respectively, Fig. 5), indicative of a rather high membrane fluidity, as previously observed [29], membranes from the rhoptry-enriched fractions displayed a significantly higher value $(\sim 0.22)$, similar to the one obtained for erythrocytes "ghosts" ( 0.20). Depletion of membrane Chol by methyl- $\beta$-cyclodextrin treatment lowered the DPH anisotropy value of membranes from parasite and erythrocyte "ghosts" and whole Toxoplasma (Fig. 5). This increase in membrane fluidity triggered by the depletion of Chol has been documented before for the erythrocytes [38] and can be explained by the order-inducing effect of this molecule for the disordered (i.e. unsaturated) acyl chains of the PL [39]. On the contrary, a less consistent effect on DPH anisotropy was observed when membranes from the rhoptry-enriched fractions were treated with methyl- $\beta$-cyclodextrin (Fig. 5). This could not be explained by a low Chol concentration, as the Chol/PL ratio is 
higher for rhoptries than for whole Toxoplasma cells for example. Instead, the presence in rhoptry membranes of high concentrations of PL with rigid acyl chains (i.e. saturated), could create a highly ordered domain where the presence of Chol would have a lesser effect on rigidity, or even rather favour membrane fluidity by weakening van der Waals' interactions between hydrocarbons chains of fatty acids and preventing crystallisation [40]. Overall, our results suggest that, in contrast to the global fluidity of the membranes from the whole Toxoplasma cell, total membranes from rhoptries (possibly including internal membranous structures [8]) appear to have a high membrane rigidity, which could be explained by the presence of saturated fatty acids in ordered lipid domains.

\section{Cholesterol and cell invasion.}

Several microbial pathogens use Chol-rich domains (for instance "raft" domains or caveolae) as a gateway for entry into their host cells [41;42]. During the process of Toxoplasma invasion, the limiting membrane from the parasite-containing PV, which is largely derived from the host cell's plasma membrane but also contains rhoptry-derived material, is known to be rich in Chol [9]. Hence, the presence of Chol in the rhoptries was initially though to be of importance for the virulence of the parasite through putative secretion at the plasma membrane or for insertion into the nascent PV [10]. These hypotheses have been tested and Chol depletion assays have shown that parasite Chol (and, in particular, from the rhoptries) was not necessary for infection, whereas host cell Chol was [9]. Our lipidomic data, indicating lower amounts of rhoptry Chol, could also point towards a low impact of rhoptry Chol from the organelle on the virulence of the parasite. Thus, we wanted to investigate more precisely if Chol could be found in secreted rhoptry material. To assess this, we took advantage of specific experimental conditions where the parasite mobility is blocked by cytochalasin D (CytD, a potent inhibitor of actin polymerisation). In these conditions, tachyzoites cannot invade, although they can bind to host cells, form a moving junction (MJ), and secrete protein-rich rhoptry-derived vesicles that can be visualised in the cytosol of the host cell and are termed "evacuoles" [7]. We could label the evacuoles through the rhoptry protein marker ROP1, and perform co-localisation experiments with filipin, a fluorescent dye specific for membrane-bound Chol (Fig. 6A). As observed previously, CytD-treated parasites displayed an apical punctate signal for the rhoptry neck protein RON4, showing that the parasites had successfully attached and formed the MJ [43]. Additionally, ROP1 was found to label clustered evacuoles forming a network extending into the host cell cytoplasm [7]. Labelling of the membrane-bound Chol with filipin highlighted the plasma membrane of the parasite and of the host cell (Fig. 6A). An intense filipin labelling could often be seen at the interface between the parasite and the host cell, which could either correspond to the apical part of the parasite or to the plasma membrane of the host cell. If present at the apex of the parasites, the filipin labelling could possibly be internal to the rhoptries; however, it is to note that the organelles were not found to be labelled in extracellular parasites, suggesting they would possess a low amount of membrane-bound cholesterol, in accordance with our lipidomic data (Table 2).

When the evacuoles clusters were close to the plasma membrane (suggesting an early time point after contact, as the evacuoles network is known to extend further into host cell with time [7]), both evacuoles and MJ were in the close vicinity of the Chol-rich region, even showing some partial co-localisation at the point of contact of the parasite (Fig. 6A). However, when the network of ROP1-positive evacuoles was more developed inside the host cell cytoplasm, no obvious co-localisation could be seen between the farthest evacuoles and filipin (Fig. 6A, bottom row), suggesting that these evacuoles are indeed not enriched in Chol. To further analyze this process, we prepared Chol-depleted parasites by growing them into fibroblasts that had been treated with statin (an inhibitor of HMG-CoA reductase in the Chol 
biosynthesis pathway) and methyl- $\beta$-cyclodextrin (a Chol-segregating drug) to lower considerably (by $\sim 70 \%$ ) their Chol content [9]. These parasites were used to assess if the Chol seen at the Toxoplasma-host cell interface is of parasite origin, by performing the same type of CytD-blocked invasion assay as described above. In these conditions, Chol could still be seen at the interface between the parasite and the host cell plasma membrane, whereas the parasite plasma membrane appeared devoid of peripheral or internal filipin labelling, suggesting efficient and considerable reduction of Chol (Fig. 6B). Both the MJ and the evacuoles were still found to be forming with Chol-depleted parasites and apart from the point of contact, no consistent co-localisation was found with the filipin signal (Fig. 6B). This would mean that the Chol-rich membranes visualised at the interface between host and parasite during the initial stages of invasion are of host origin. It could either be that the parasite is preferentially selecting Chol-rich domains of the host's plasma membrane to initiate invasion, or that Toxoplasma could trigger the recruitment of host Chol at the site of invasion. This could be mediated simply by lateral diffusion through the membrane, by vesicle-mediated transport, or a soluble protein carrier (see [44] for a review).

Finally, as filipin-labeled Chol was found close to the MJ at the point of contact between Toxoplasma and the host cell, we wanted to assess if the junction remains bound to Chol-rich membranes during parasite invasion. Invasions were then performed without CytD (Fig. 7), to allow the active penetration of the tachyzoites. Filipin was generally not found to be colocalising with the MJ throughout the invasive process and with the residual junction found on the recently closed PVM [43], although it was found together with ROP1 at the PVM as described before [9].

Not only has the PVM been found to be enriched in Chol at the time of invasion by Toxoplasma [9], but it has also been shown to incorporate several other host cell membrane reporter molecules belonging to Chol-rich raft (i.e. GPI-anchored proteins CD55, GPIICAM1, GM1 ganglioside or DiIC 16 lipid), and also to non-raft lipid domains (i.e. tailless ICAM1 protein, FAST DiOC $_{18}$ lipid) [12]. Although the MJ could play a role in sorting the protein components of raft domains (such as GPI-anchored proteins) to be incorporated into the PVM [11], we have shown that the MJ itself does not seem to be co-localising with Cholrich domains of the host cell during invasion. In Plasmodium, several raft-associated host proteins seem to be dispensable for parasite infection, but total raft depletion blocks parasite entry [45]. Similarly, depletion of Chol from the host cell totally blocks invasion by Toxoplasma [9], suggesting that host lipid rafts could have a role in invasion. Our finding that Chol-rich membranes can be visualised at the interface between Toxoplasma and its host cell seems to go along the same line. However, the fact that they can still be observed when using Chol-depleted parasites, that the parasite-derived evacuoles do not seem to be enriched in Chol, and that, as observed before [9], Chol-depleted Toxoplasma can still invade its host cell suggests little or no involvement of rhoptry Chol in invasion.

Conclusion. The lipid composition of Toxoplasma tachyzoites and of their rhoptries has been the object of a few past studies, which were aiming at determining the composition and properties of the membranes from this pathogen and these organelles that are considered important for virulence. With improved technological tools at hand, our data provided a more exhaustive analysis and substantial additional information. Our study revealed several features of the rhoptries lipidome: i) globally, we found a lower lipid to protein ratio in the rhoptries than for the whole tachyzoites, suggesting a rather rich protein content of the organelle. ii) choline-containing PL (i.e. PC, SM) appear to be highly represented, with a lower percentage of PE and no detectable PS. iii) low levels of TAG likely reflect an absence of lipid bodies in the organelle. iv) FA analysis of the whole lipids revealed that there was a high proportion of 
short chain and highly saturated FA. v) in contrast with previous studies, we did not find a particularly high enrichment of $\mathrm{Chol}$ in the rhoptries.

Consistent with this, our study confirmed that the role played by the Chol in the rhoptries does not appear to be essential for the virulence of the tachyzoites, contrarily to host cell Chol which seems to be present at the contact point between parasite and the plasma membrane during early stages of invasion. A major challenge is now to understand the precise role of host cell Chol and the molecular interactions between host and parasite lipids during invasion. On the other hand, Chol may have, along with SM and the particularly abundant SAFA, a structural role for the organelle. Indeed, the presence of such lipids, assuming they would be incorporated into the rhoptry membranes is likely to affect their physical properties, which, as we have shown, are rather rigid compared to the global membranous content of the parasite and this might contribute to the so peculiar elongated morphology of rhoptries. In contrast, high membrane fluidity of the tachyzoites might be essential for the plasticity of their plasma membrane, as they undergo extensive deformability during host cell invasion. It might also facilitate the movement of surface adhesive proteins which are translocated along the parasite cell body during the invasion process.

Finally, our results reflect a global lipidomic analysis of the organelle and obviously, there must be local variations within membrane domains of the rhoptries. For instance, these organelles appear to be highly polarised, as they harbour proteins that are specifically localised to their neck (RON) or bulbous parts (ROP), which seem to have different roles for invasion or the establishment of the parasite in the PV and hence could be secreted sequentially in time. Thus, rhoptry lipids might be involved in sorting and segregation of these proteins. There are several examples where the lipidic composition of the membranes drives protein sorting and trafficking such as in the photoreceptor rod, where there is a Chol and FA unsaturation gradient conferring different physical properties and functional roles to the organelle [46] or with the cis to trans Chol gradient of the Golgi [47]. The lipids we detected in the rhoptries might also be present into internal structures that could be involved in the packaging of the proteins. Indeed, solubilisation treatments of the organelle show that many rhoptry proteins could be embedded in membranes [2]. Some of these might be resident proteins of the rhoptries and structural component of the membrane, but others such as ROP2 [48], are known to be secreted after invasion. Hence, an additional role of rhoptry lipids could be organising and packing the insoluble rhoptry proteins as lipoproteins or within vesicular membranes, before secretion into the host cell. Rhoptry Chol does not appear to be essential for secretion of RON or ROP proteins, but determining the lipid sub-domains within the rhoptry and the putative role of local lipids in sorting or secreting those proteins is certainly a future objective to further characterise the many virulence factors present in the organelle.

\section{Acknowledgements.}

Our thanks go to Dr Angel for contributing antibodies. We also gratefully acknowledge Veronique Roques for helpful assistance at the lipidomic plateform. This work was supported by the CNRS, the INSERM and ANR grant 06-MIME-024-01. 


\section{References.}

1 Dubremetz, J. F., Garcia-Reguet, N., Conseil, V., and Fourmaux, M. N. (1998) Apical organelles and host-cell invasion by Apicomplexa. Int.J Parasitol. 28, 1007-1013

2 Bradley, P. J., Ward, C., Cheng, S. J., Alexander, D. L., Coller, S., Coombs, G. H., Dunn, J. D., Ferguson, D. J., Sanderson, S. J., Wastling, J. M., and Boothroyd, J. C. (2005) Proteomic analysis of rhoptry organelles reveals many novel constituents for host-parasite interactions in Toxoplasma gondii. J Biol.Chem. 280, 34245-34258

3 El Hajj, H., Lebrun, M., Arold, S. T., Vial, H., Labesse, G., and Dubremetz, J. F. (2007) ROP18 is a rhoptry kinase controlling the intracellular proliferation of Toxoplasma gondii. PLoS.Pathog. 3, e14

4 Saeij, J. P., Boyle, J. P., Coller, S., Taylor, S., Sibley, L. D., Brooke-Powell, E. T., Ajioka, J. W., and Boothroyd, J. C. (2006) Polymorphic secreted kinases are key virulence factors in toxoplasmosis. Science 314, 1780-1783

5 Saeij, J. P., Coller, S., Boyle, J. P., Jerome, M. E., White, M. W., and Boothroyd, J. C. (2007) Toxoplasma co-opts host gene expression by injection of a polymorphic kinase homologue. Nature 445, 324-327

6 Taylor, S., Barragan, A., Su, C., Fux, B., Fentress, S. J., Tang, K., Beatty, W. L., Hajj, H. E., Jerome, M., Behnke, M. S., White, M., Wootton, J. C., and Sibley, L. D. (2006) A secreted serine-threonine kinase determines virulence in the eukaryotic pathogen Toxoplasma gondii. Science 314, 1776-1780

7 Hakansson, S., Charron, A. J., and Sibley, L. D. (2001) Toxoplasma evacuoles: a twostep process of secretion and fusion forms the parasitophorous vacuole. EMBO J 20 , 3132-3144

8 Nichols, B. A., Chiappino, M. L., and O'Connor, G. R. (1983) Secretion from the rhoptries of Toxoplasma gondii during host-cell invasion. J Ultrastruct.Res. 83, 85-98

9 Coppens, I. and Joiner, K. A. (2003) Host but not parasite cholesterol controls Toxoplasma cell entry by modulating organelle discharge. Mol.Biol.Cell 14, 3804-3820

10 Foussard, F., Leriche, M. A., and Dubremetz, J. F. (1991) Characterization of the lipid content of Toxoplasma gondii rhoptries. Parasitology 102 Pt 3, 367-370

11 Mordue, D. G., Desai, N., Dustin, M., and Sibley, L. D. (1999) Invasion by Toxoplasma gondii establishes a moving junction that selectively excludes host cell plasma membrane proteins on the basis of their membrane anchoring. J Exp.Med. 190, 17831792

12 Charron, A. J. and Sibley, L. D. (2004) Molecular partitioning during host cell penetration by Toxoplasma gondii. Traffic 5, 855-867

13 Donald, R. G., Carter, D., Ullman, B., and Roos, D. S. (1996) Insertional tagging, cloning, and expression of the Toxoplasma gondii hypoxanthine-xanthine-guanine phosphoribosyltransferase gene. Use as a selectable marker for stable transformation. J Biol.Chem. 271, 14010-14019 
14 Leriche, M. A. and Dubremetz, J. F. (1991) Characterization of the protein contents of rhoptries and dense granules of Toxoplasma gondii tachyzoites by subcellular fractionation and monoclonal antibodies. Mol.Biochem.Parasitol. 45, 249-259

15 El Hajj, H., Lebrun, M., Fourmaux, M. N., Vial, H., and Dubremetz, J. F. (2007) Inverted topology of the Toxoplasma gondii ROP5 rhoptry protein provides new insights into the association of the ROP2 protein family with the parasitophorous vacuole membrane. Cell Microbiol. 9, 54-64

16 de Miguel, N., Echeverria, P. C., and Angel, S. O. (2005) Differential subcellular localization of members of the Toxoplasma gondii small heat shock protein family. Eukaryot.Cell 4, 1990-1997

17 Bermudes, D., Dubremetz, J. F., Achbarou, A., and Joiner, K. A. (1994) Cloning of a cDNA encoding the dense granule protein GRA3 from Toxoplasma gondii.

Mol.Biochem.Parasitol. 68, 247-257

18 Couvreur, G., Sadak, A., Fortier, B., and Dubremetz, J. F. (1988) Surface antigens of Toxoplasma gondii. Parasitology 97 ( Pt 1), 1-10

19 Bligh, E. G. and Dyer, W. J. (1959) A rapid method of total lipid extraction and purification. Can.J Biochem.Physiol 37, 911-917

20 Barrans, A., Collet, X., Barbaras, R., Jaspard, B., Manent, J., Vieu, C., Chap, H., and Perret, B. (1994) Hepatic lipase induces the formation of pre-beta 1 high density lipoprotein (HDL) from triacylglycerol-rich HDL2. A study comparing liver perfusion to in vitro incubation with lipases. J Biol.Chem. 269, 11572-11577

21 Vieu, C., Terce, F., Chevy, F., Rolland, C., Barbaras, R., Chap, H., Wolf, C., Perret, B., and Collet, X. (2002) Coupled assay of sphingomyelin and ceramide molecular species by gas liquid chromatography. J Lipid Res. 43, 510-522

22 Lillington, J. M., Trafford, D. J., and Makin, H. L. (1981) A rapid and simple method for the esterification of fatty acids and steroid carboxylic acids prior to gas-liquid chromatography. Clin.Chim.Acta 111, 91-98

23 Shinitzky, M. and Barenholz, Y. (1978) Fluidity parameters of lipid regions determined by fluorescence polarization. Biochim.Biophys.Acta 515, 367-394

24 Blisnick, T., Morales Betoulle, M. E., Barale, J. C., Uzureau, P., Berry, L., Desroses, S., Fujioka, H., Mattei, D., and Braun, B. C. (2000) Pfsbp1, a Maurer's cleft Plasmodium falciparum protein, is associated with the erythrocyte skeleton. Mol.Biochem.Parasitol. 111, $107-121$

25 Sadak, A., Taghy, Z., Fortier, B., and Dubremetz, J. F. (1988) Characterization of a family of rhoptry proteins of Toxoplasma gondii. Mol.Biochem.Parasitol. 29, 203-211

26 Ngo, H. M., Yang, M., and Joiner, K. A. (2004) Are rhoptries in Apicomplexan parasites secretory granules or secretory lysosomal granules? Mol.Microbiol. 52, 15311541 
27 Welti, R., Mui, E., Sparks, A., Wernimont, S., Isaac, G., Kirisits, M., Roth, M., Roberts, C. W., Botte, C., Marechal, E., and McLeod, R. (2007) Lipidomic analysis of Toxoplasma gondii reveals unusual polar lipids. Biochemistry 46, 13882-13890

28 Mazumdar, J. and Striepen, B. (2007) Make it or take it: fatty acid metabolism of apicomplexan parasites. Eukaryot.Cell 6, 1727-1735

29 Gallois, Y., Foussard, F., Girault, A., Hodbert, J., Tricaud, A., Mauras, G., and Motta, C. (1988) Membrane fluidity of Toxoplasma gondii: a fluorescence polarization study. Biol.Cell 62, 11-15

30 Maxfield, F. R. and Tabas, I. (2005) Role of cholesterol and lipid organization in disease. Nature 438, 612-621

31 Nishikawa, Y., Quittnat, F., Stedman, T. T., Voelker, D. R., Choi, J. Y., Zahn, M., Yang, M., Pypaert, M., Joiner, K. A., and Coppens, I. (2005) Host cell lipids control cholesteryl ester synthesis and storage in intracellular Toxoplasma. Cell Microbiol. 7, 849-867

32 Athenstaedt, K. and Daum, G. (2006) The life cycle of neutral lipids: synthesis, storage and degradation. Cell Mol.Life Sci. 63, 1355-1369

33 Zweytick, D., Athenstaedt, K., and Daum, G. (2000) Intracellular lipid particles of eukaryotic cells. Biochim.Biophys.Acta 1469, 101-120

34 Coppens, I. and Vielemeyer, O. (2005) Insights into unique physiological features of neutral lipids in Apicomplexa: from storage to potential mediation in parasite metabolic activities. Int.J Parasitol. 35, 597-615

35 Bloom, M., Evans, E., and Mouritsen, O. G. (1991) Physical properties of the fluid lipid-bilayer component of cell membranes: a perspective. Q.Rev.Biophys. 24, 293-397

36 Stubbs, C. D. and Smith, A. D. (1984) The modification of mammalian membrane polyunsaturated fatty acid composition in relation to membrane fluidity and function. Biochim.Biophys.Acta 779, 89-137

37 Foussard, F., Gallois, Y., Girault, A., and Menez, J. F. (1991) Lipids and fatty acids of tachyzoites and purified pellicles of Toxoplasma gondii. Parasitol.Res. 77, 475-477

38 Chabanel, A., Flamm, M., Sung, K. L., Lee, M. M., Schachter, D., and Chien, S. (1983) Influence of cholesterol content on red cell membrane viscoelasticity and fluidity. Biophys.J 44, 171-176

39 Mouritsen, O. G. and Zuckermann, M. J. (2004) What's so special about cholesterol? Lipids 39, 1101-1113

40 Oldfield, E. and Chapman, D. (1972) Dynamics of lipids in membranes: Heterogeneity and the role of cholesterol. FEBS Lett. 23, 285-297

Manes, S., del Real, G., and Martinez, A. (2003) Pathogens: raft hijackers. Nat.Rev.Immunol 3, 557-568 
42 Wenk, M. R. (2006) Lipidomics of host-pathogen interactions. FEBS Lett. 580, 55415551

43 Lebrun, M., Michelin, A., El Hajj, H., Poncet, J., Bradley, P. J., Vial, H., and Dubremetz, J. F. (2005) The rhoptry neck protein RON4 re-localizes at the moving junction during Toxoplasma gondii invasion. Cell Microbiol. 7, 1823-1833

44 Maxfield, F. R. and Wustner, D. (2002) Intracellular cholesterol transport. J Clin.Invest 110, 891-898

45 Murphy, S. C., Hiller, N. L., Harrison, T., Lomasney, J. W., Mohandas, N., and Haldar, K. (2006) Lipid rafts and malaria parasite infection of erythrocytes. Mol.Membr.Biol. 23, $81-88$

46 Albert, A. D. and Boesze-Battaglia, K. (2005) The role of cholesterol in rod outer segment membranes. Prog.Lipid Res. 44, 99-124

47 Orci, L., Montesano, R., Meda, P., Malaisse-Lagae, F., Brown, D., Perrelet, A., and Vassalli, P. (1981) Heterogeneous distribution of filipin- cholesterol complexes across the cisternae of the Golgi apparatus. Proc.Natl.Acad.Sci.U.S.A 78, 293-297

48 Beckers, C. J., Dubremetz, J. F., Mercereau-Puijalon, O., and Joiner, K. A. (1994) The Toxoplasma gondii rhoptry protein ROP 2 is inserted into the parasitophorous vacuole membrane, surrounding the intracellular parasite, and is exposed to the host cell cytoplasm. J Cell Biol. 127, 947-961

49 Dodge, J. T. and Phillips, G. B. (1967) Composition of phospholipids and of phospholipid fatty acids and aldehydes in human red cells. J Lipid Res. 8, 667-675 
Tables and figures. 


\begin{tabular}{|c|c|c|}
\hline & Whole tachyzoites $(n=3)$ & Rhoptries $(n=4)$ \\
\hline \multicolumn{3}{|l|}{ SAFA } \\
\hline $14: 0$ & $87.02 \pm 10.05$ & $30.55 \pm 13.23$ \\
\hline 15:0 & nd & nd \\
\hline $16: 0$ & $423.91 \pm 5.54$ & $399.09 \pm 62.67$ \\
\hline $18: 0$ & $139.12 \pm 44.21$ & $219.56 \pm 42.68$ \\
\hline 20:0 & $8.49 \pm 0.92$ & $13.14 \pm 4.90$ \\
\hline 21:0 & nd & nd \\
\hline 22:0 & $0.36 \pm 0.48$ & nd \\
\hline 23:0 & nd & nd \\
\hline 24:0 & $3.86 \pm 0.90$ & nd \\
\hline Total & $662.76 \pm 61.20$ & $662.34 \pm 123.48$ \\
\hline \multicolumn{3}{|l|}{ MUFA } \\
\hline $14: 1 n-5$ & nd & nd \\
\hline $15: 1 n-5$ & nd & nd \\
\hline $16: 1 n-7$ & $83.08 \pm 16.37$ & $23.63 \pm 2.41$ \\
\hline $17: 1 n-7$ & nd & nd \\
\hline $18: 1 n-9$ & $517.90 \pm 114.13$ & $235.97 \pm 15.00$ \\
\hline $18: 1 n-7$ & nd & nd \\
\hline $20: 1 n-9$ & $29.27 \pm 4.85$ & $0.71 \pm 1.05$ \\
\hline $22: 1 n-9$ & $0.30 \pm 0.40$ & nd \\
\hline $24: 1 n-9$ & $1.45 \pm 0.29$ & nd \\
\hline Total & $632 \pm 136.04$ & $260.31 \pm 18.46$ \\
\hline \multicolumn{3}{|l|}{ PUFA } \\
\hline $18: 2 n-6$ & $73.43 \pm 16.64$ & $34.69 \pm 18.23$ \\
\hline $18: 3 n-6$ & nd & nd \\
\hline $18: 3 n-3$ & $3.35 \pm 0.61$ & nd \\
\hline $20: 2 n-6$ & $3.02 \pm 0.55$ & nd \\
\hline $20: 3 n-3$ & nd & nd \\
\hline $20: 3 n-6$ & $4.37 \pm 1.44$ & nd \\
\hline $20: 4 n-6$ & $20.13 \pm 4.53$ & nd \\
\hline $20: 5 n-3$ & $2.24 \pm 0.62$ & nd \\
\hline $22: 5 n-3$ & nd & nd \\
\hline $22: 2 n-6$ & nd & nd \\
\hline $22: 6 n-3$ & $4.72 \pm 1.15$ & nd \\
\hline Total & $111.26 \pm 25.54$ & $34.69 \pm 18.23$ \\
\hline
\end{tabular}

Table 1. Fatty acid composition of the whole tachyzoites and rhoptry-enriched extracts. Results are in nmol of lipid per mg of protein \pm SEM. nd: not detected. SAFA, saturated fatty acids; MUFA, monounsaturated fatty acids; PUFA, polyunsaturated fatty acids. 


\begin{tabular}{|l|c|c|}
\cline { 2 - 3 } \multicolumn{1}{c|}{} & Whole tachyzoites $(n=5)$ & Rhoptries $(n=4)$ \\
\hline Cholesterol & $81.19 \pm 13.92$ & $31.30 \pm 4.79$ \\
\hline C14 & nd & nd \\
C18 & $2.92 \pm 0.79$ & $0.19 \pm 0.23$ \\
C20:4 & $4.26 \pm 0.73$ & $0.75 \pm 0.33$ \\
C22 & $0.23 \pm 0.37$ & $0.03 \pm 0.05$ \\
\hline Total CE & nd & nd \\
\hline C33 & $7.41 \pm 1.89$ & $0.98 \pm 0.61$ \\
C35 & $4.66 \pm 0.92$ & $3.07 \pm 0.67$ \\
C37 & $6.16 \pm 0.70$ & $2.09 \pm 0.43$ \\
C39 & $3.09 \pm 0.70$ & $3.10 \pm 0.23$ \\
C41 & $0.65 \pm 0.36$ & $1.16 \pm 0.28$ \\
C43 & nd & $0.35 \pm 0.25$ \\
\hline Total DAG & $20.76 \pm 3.11$ & nd \\
\hline C49 & $6.92 \pm 0.77$ & $9.77 \pm 1.86$ \\
C51 & $7.91 \pm 0.59$ & $1.17 \pm 0.91$ \\
C53 & $9.57 \pm 0.42$ & $0.44 \pm 0.53$ \\
C55 & $7.53 \pm 0.66$ & $0.65 \pm 0.60$ \\
C57 & $3.66 \pm 0.37$ & $0.47 \pm 0.62$ \\
C59 & $0.27 \pm 0.42$ & $0.25 \pm 0.39$ \\
\hline Total TAG & $35.85 \pm 3.23$ & $0.06 \pm 0.10$ \\
\hline
\end{tabular}

Table 2. Neutral lipids composition of the whole tachyzoites and rhoptry-enriched extracts. Results are in nmol of lipid per mg of protein \pm SEM. nd: not detected. CE, cholesteryl esters; DAG, diacylglycerides; TAG, triacylglycerides. DAG and TAG molecules were separated and named according to their total number of carbons. 


\begin{tabular}{|l|c|c|c|}
\cline { 2 - 4 } \multicolumn{1}{c|}{} & Chol/PL & SM/PC & SAFA/UFA \\
\hline Erythrocytes $^{*}$ & 0.8 & 0.87 & 1.35 \\
\hline Whole tachyzoites & 0.24 & 0.18 & 0.9 \\
\hline Rhoptry fraction & 0.34 & 0.32 & 2.24 \\
\hline
\end{tabular}

Table 3. Lipid ratios from erythrocytes, whole tachyzoites and rhoptry-enriched fraction. Chol, cholesterol; PL, phospholipids; SM, sphingomyelin; PC, phosphatidylcholine; SAFA, saturated fatty acids; UFA, unsaturated fatty acids.

* data derived from Dodge and Phillips [49] 
Figure 1. Isolation of a rhoptry-enriched fraction from T. gondii tachyzoites. A. Scheme of the organellar fractions obtained after Percoll gradient. Densities are indicated on the left $(\mathrm{g} / \mathrm{ml})$ B. Assessment by Western blot of the purity of the fractions using antibodies against protein markers of the rhoptries (ROP5), mitochondria (HSP28), dense granules (GRA3) and plasma membrane (SAG1). $15 \mu \mathrm{g}$ of total proteins were loaded in each lane. C. Relative enrichment of each fraction compared to a tachyzoite cell extract. Band densitometry analysis was performed after Western blot analyses comparable to the one shown in B and band densities in each fraction were expressed relatively to whole tachyzoite extracts, reflecting the relative enrichment of each marker in the fractions. Highest values in fractions for each organellar marker are in bold. Data are mean \pm SEM from two independent rhoptry preparations on which $n$ Western blot analyses were performed.

Figure 2. Analysis of the phospholipids present in whole tachyzoites extracts and rhoptryenriched fractions. A. Total amounts of the different phospholipids subclasses (PE, phosphatidylethanolamine; PC, phosphatidylcholine; PG, phosphatidylglycerol; PS, phosphatidylserine; PI, phosphatidylinositol; LPL, lysophospholipids; SM, sphingomyelin) in the extracts. ": might be PG, but could not be unambiguously identified due to a shift in the corresponding peak. Sphingomyelin species were analysed separately by gas-liquid chromatography (see Experimental section). B. Proportions of the different subclasses compared to the total amount of phospholipids present in the extracts. Data represent the mean from independent experiments (tachyzoites, $n=5$; rhoptries, $n=3$ ), \pm SEM. * $p<0.05$ (Student's T-test).

Figure 3. Proportions of saturated (SAFA), mono-unsaturated (MUFA) and poly-unsaturated fatty acids (PUFA) compared to the total amount of fatty acids present in the extracts. Data represent the mean from independent experiments (tachyzoites, $n=3$; rhoptries, $n=4$ ), \pm SEM. $*: p<0.05$ or $* *: p<0.005$ (Student's T-test).

Figure 4. Proportions of cholesterol (Chol), cholesteryl esters (CE), diacylglycerides (DAG) and triacylglycerides (TAG), compared to the total amount of neutral lipids measured in the extracts. Data represent the mean from several independent experiments (tachyzoites, $n=5$; rhoptries, $n=4)$, \pm SEM.

Figure 5. Analysis of membrane fluidity by analysis of DPH anisotropy in T. gondii tachyzoites, $T$. gondii ghosts from fraction I, rhoptries isolated from fraction III, values for erythrocyte ghosts are indicated as a reference. Extracts were previously treated or not with Chol-segregating drug methyl- $\beta$-cyclodextrin $(\mathrm{M} \beta \mathrm{CD})$. Data represent the mean from four independent experiments \pm SEM. $*: p<0.05$ or **: $p<0.005$ (Student's T-test).

Figure 6. Cholesterol localisation during invasion in cytochalasin D-treated tachyzoites. A. Membrane-bound cholesterol was labeled with filipin (fil), the evacuoles with an anti-ROP1 antibody and the moving junction with an anti-RON4 antibody. Arrowheads point the zone were co-localisation can be seen. B. Cholesterol-depleted parasites were used for invasion. Scale bar $=5 \mu \mathrm{m}$.

Figure 7. Fate of cholesterol during invasion in permissive conditions. Membrane-bound cholesterol was labeled with filipin (fil), the parasitophorous vacuole membrane with an antiROP1 antibody and the moving junction with an anti-RON4 antibody. Scale bar=5 $\mu \mathrm{m}$. 

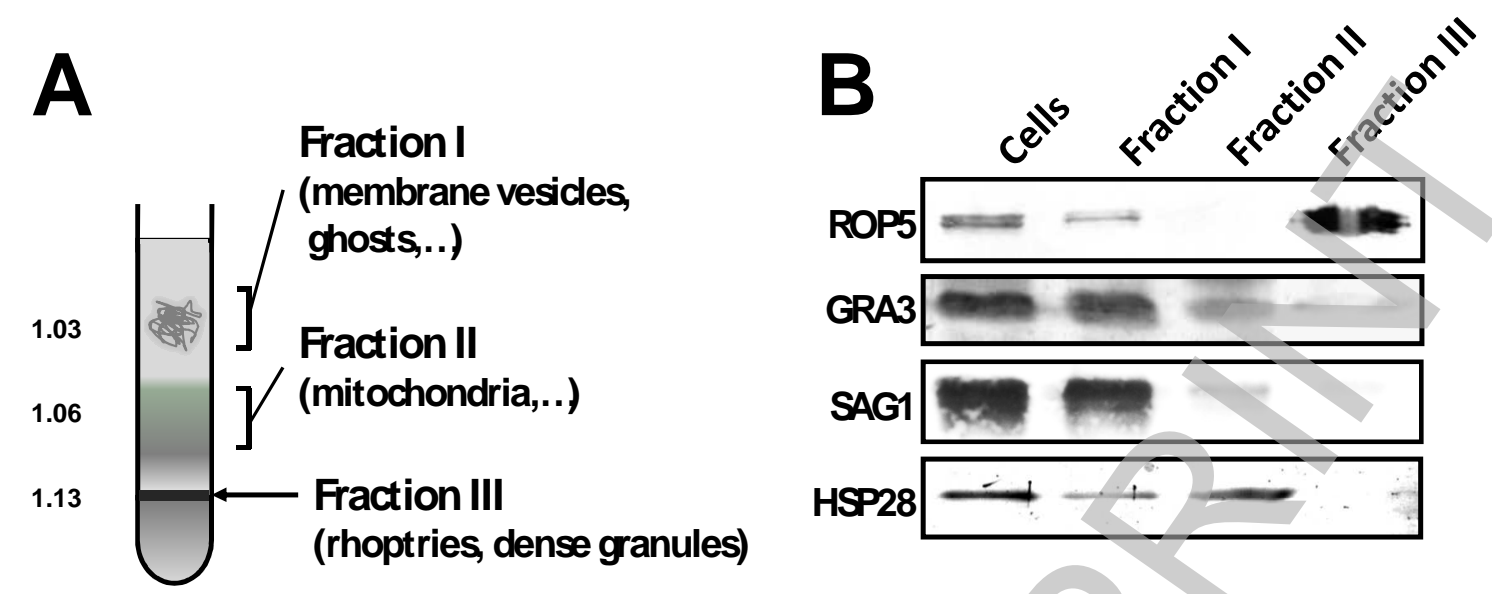

Figure 1.

\begin{tabular}{|c|cccc|}
\cline { 2 - 5 } \multicolumn{1}{c|}{} & Cells & Fraction I & Fraction II & Fraction III \\
\hline ROP5 $(n=7)$ & 1 & $0.35 \pm 0.05$ & $0.07 \pm 0.03$ & $\mathbf{6 . 6 \pm 1 . 1}$ \\
GRA3 $(n=6)$ & 1 & $\mathbf{0 . 8 0} \pm \mathbf{0 . 1 3}$ & $0.36 \pm 0.11$ & $0.30 \pm 0.05$ \\
SAG1 $(n=4)$ & 1 & $\mathbf{1 . 2 0} \pm \mathbf{0 . 1 8}$ & $0.08 \pm 0.014$ & $0.013 \pm 0.005$ \\
HSP28 $(n=4)$ & 1 & $0.50 \pm 0.30$ & $1.1 \pm 0.24$ & $0.05 \pm 0.02$ \\
\hline
\end{tabular}



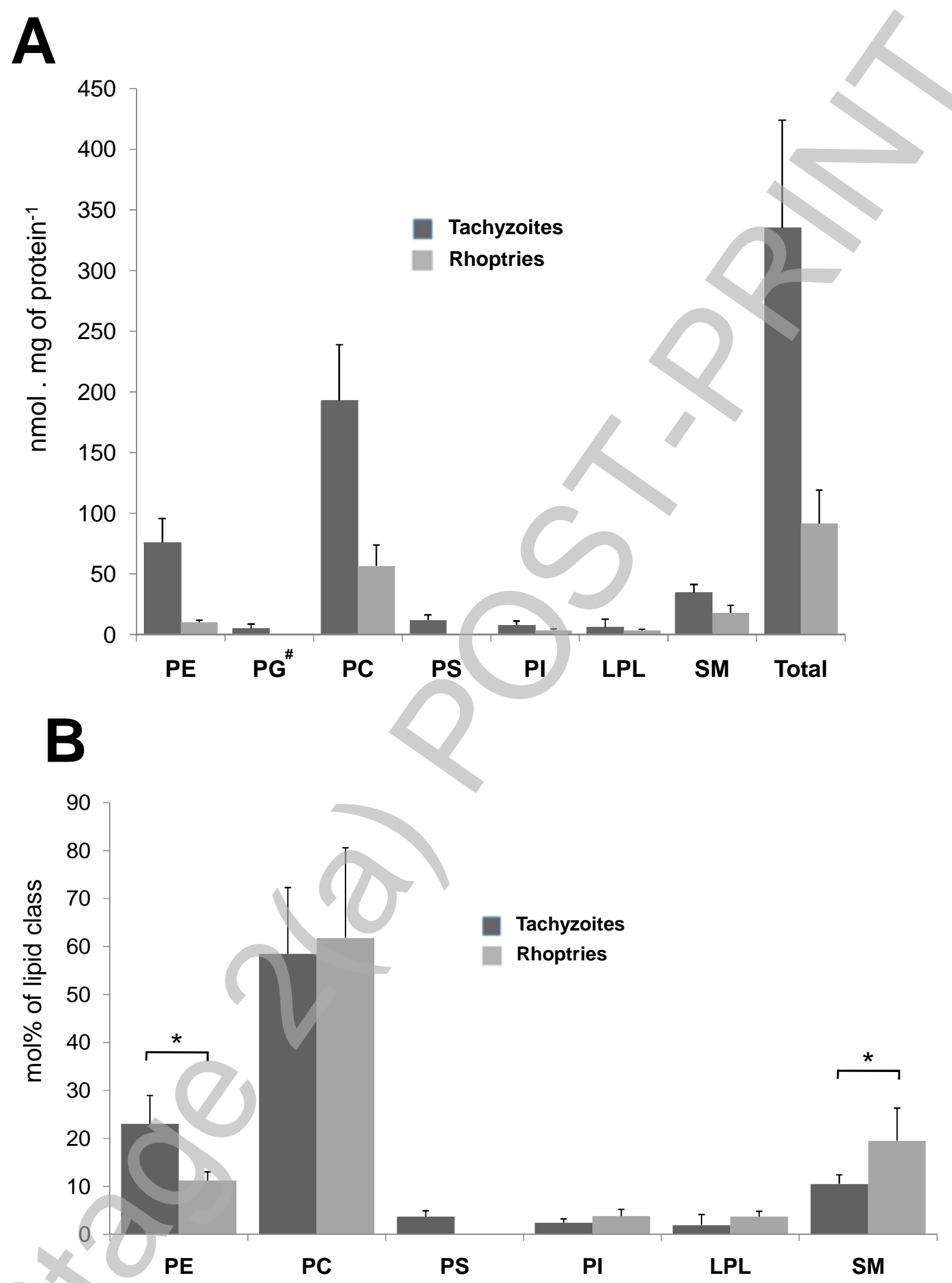

Figure 2. 


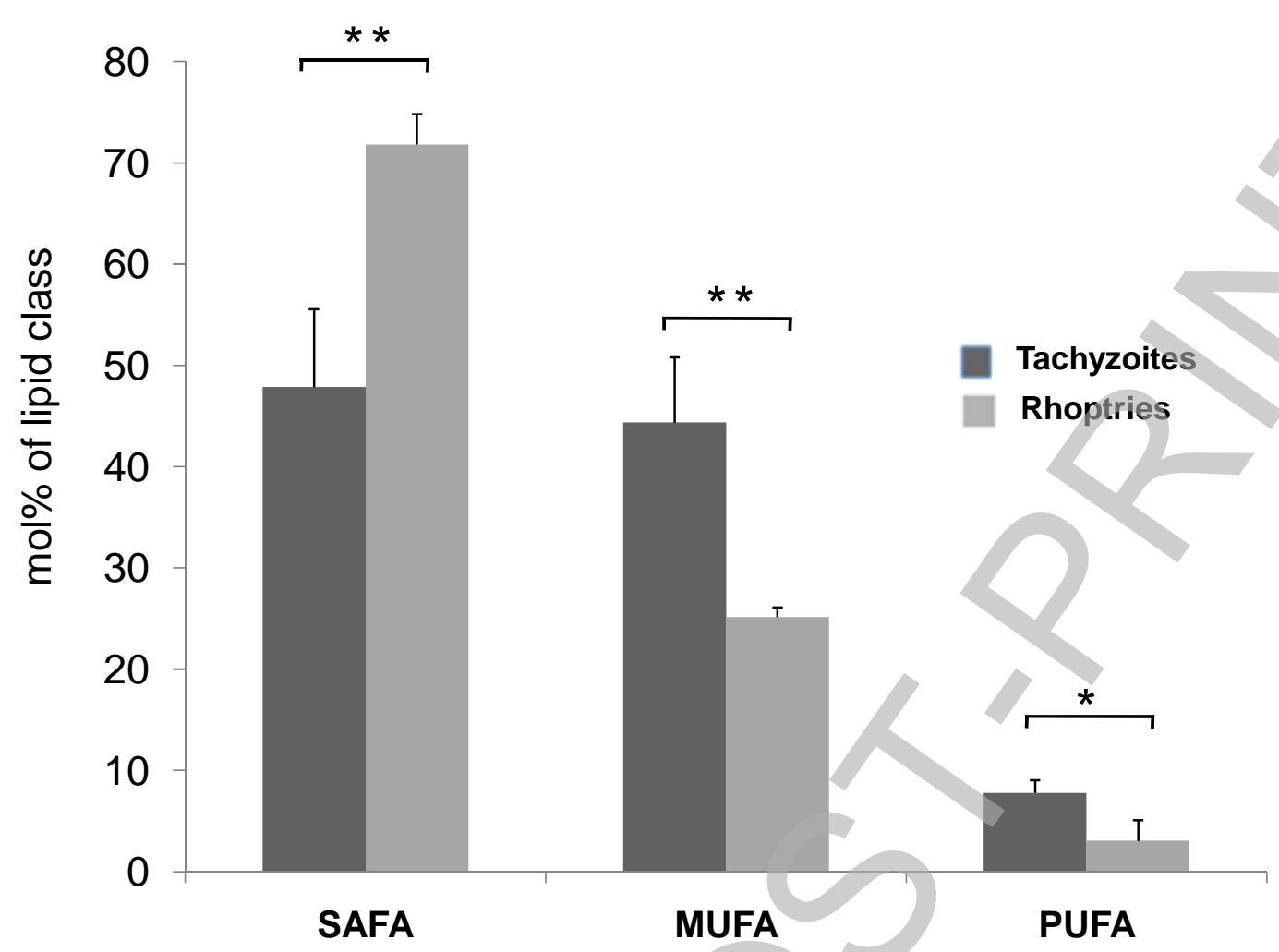

Figure 3. 


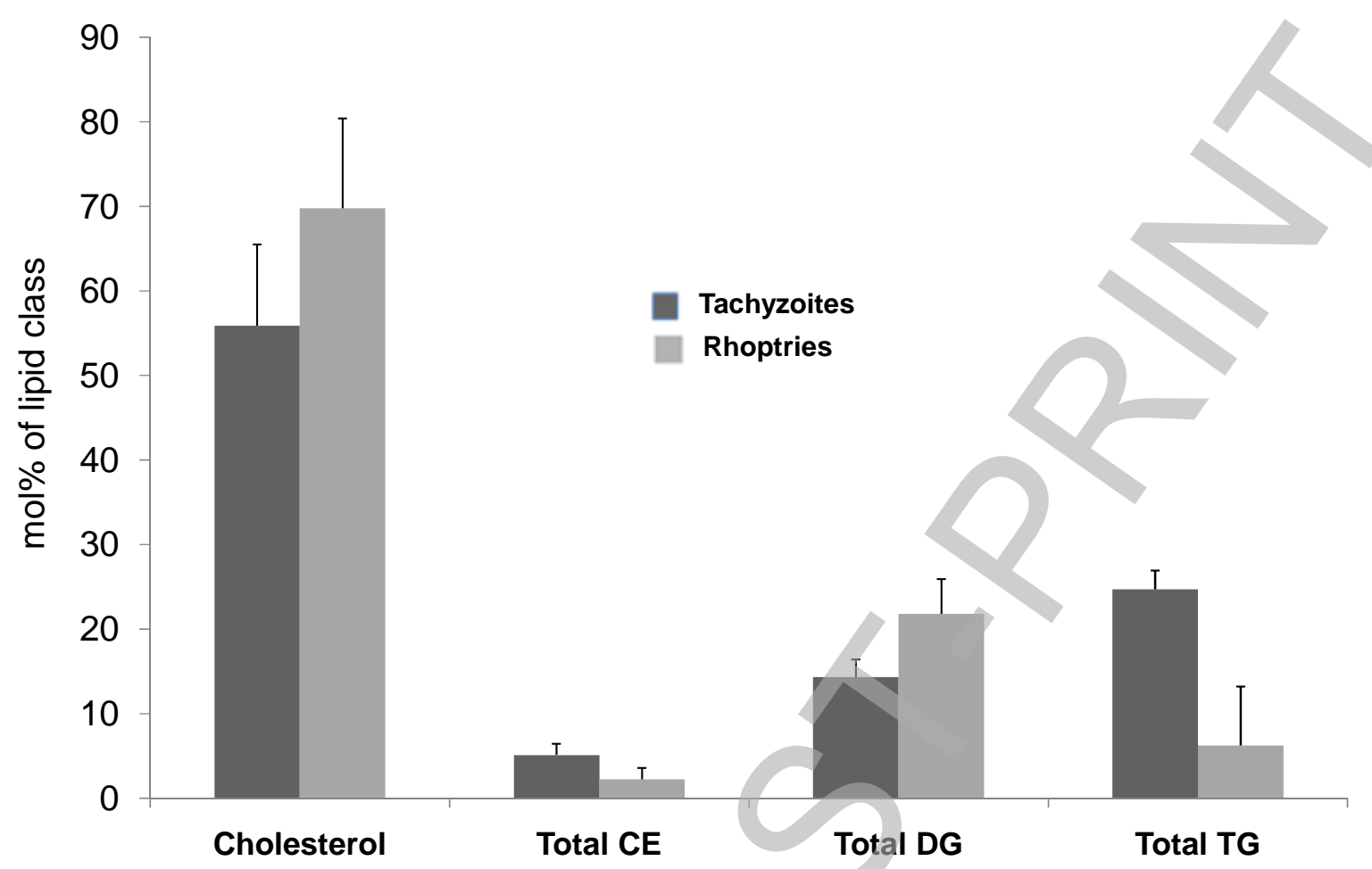

Figure 4. 


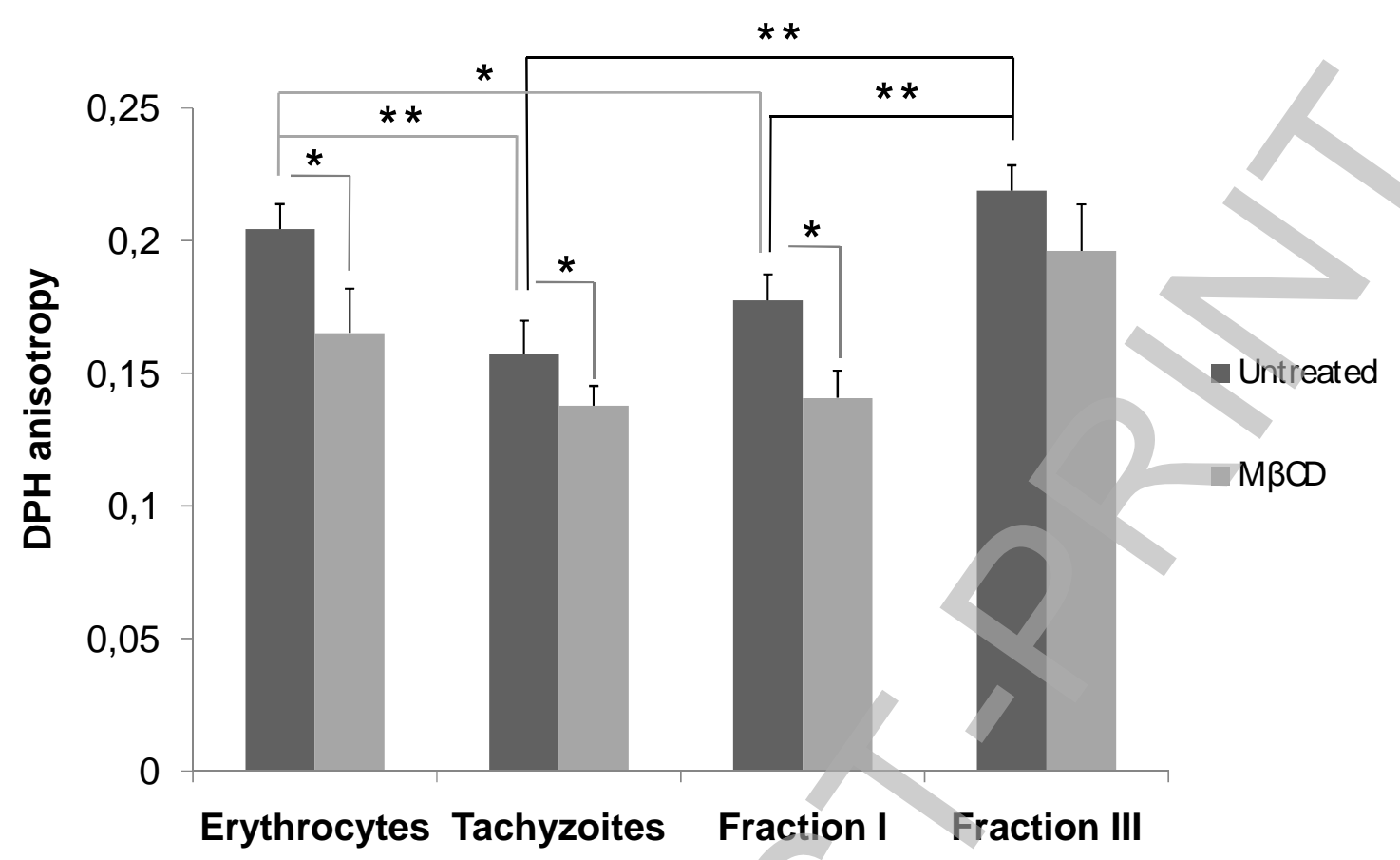

Figure 5. 
B Biochemical Journal Immediate Publication. Published on 16 Jun 2008 as manuscript BJ20080795
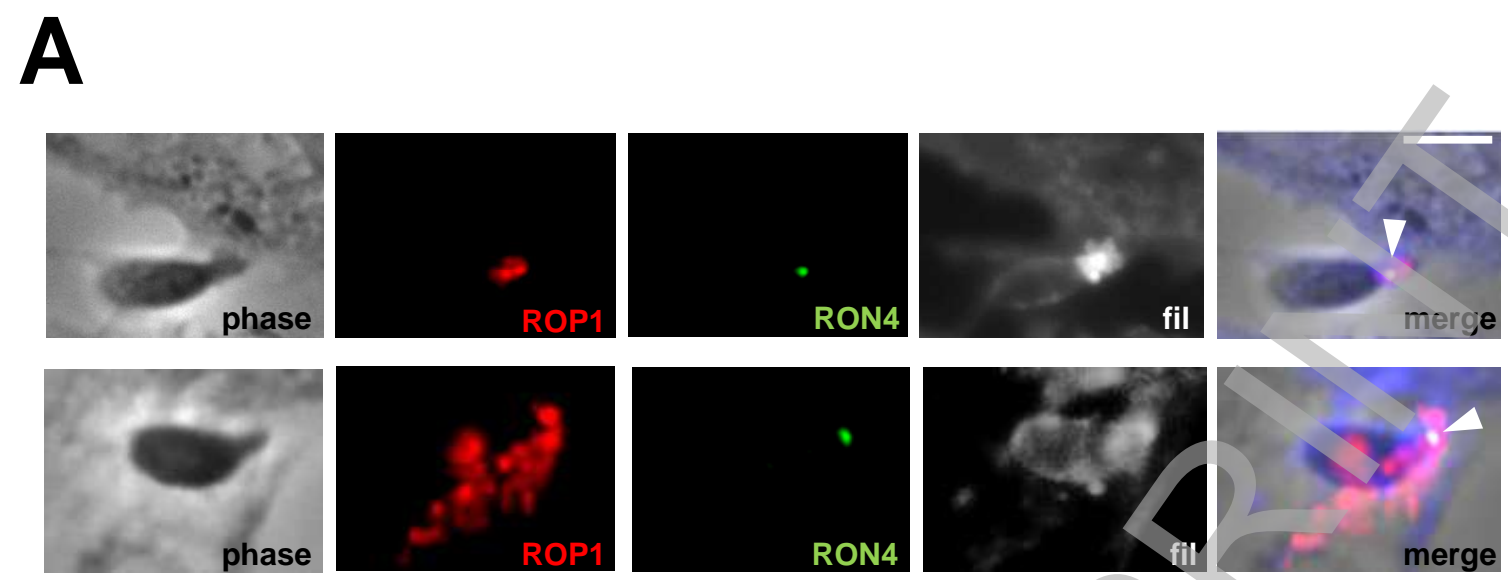

B
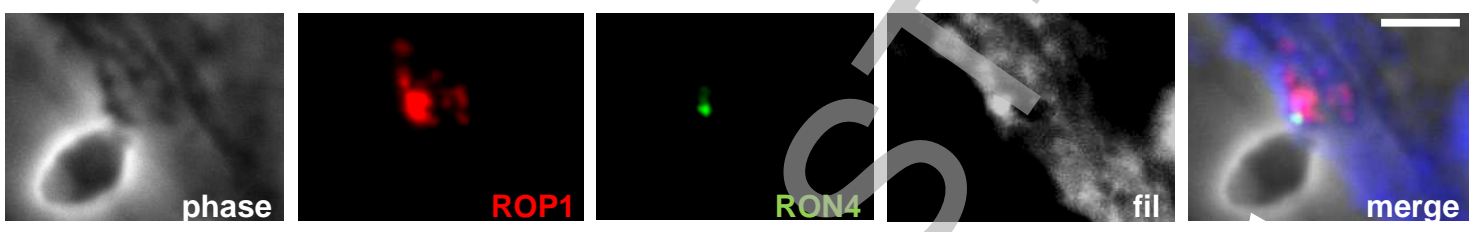

Figure 6.

$$
\text { - } 26 \text { - }
$$

Licenced copy. Copying is not permitted, except with prior permission and as allowed by law. ' 2008 The Authors Journal compilation ' 2008 Biochemical Society 
B) Biochemical Journal Immediate Publication. Published on 16 Jun 2008 as manuscript BJ20080795
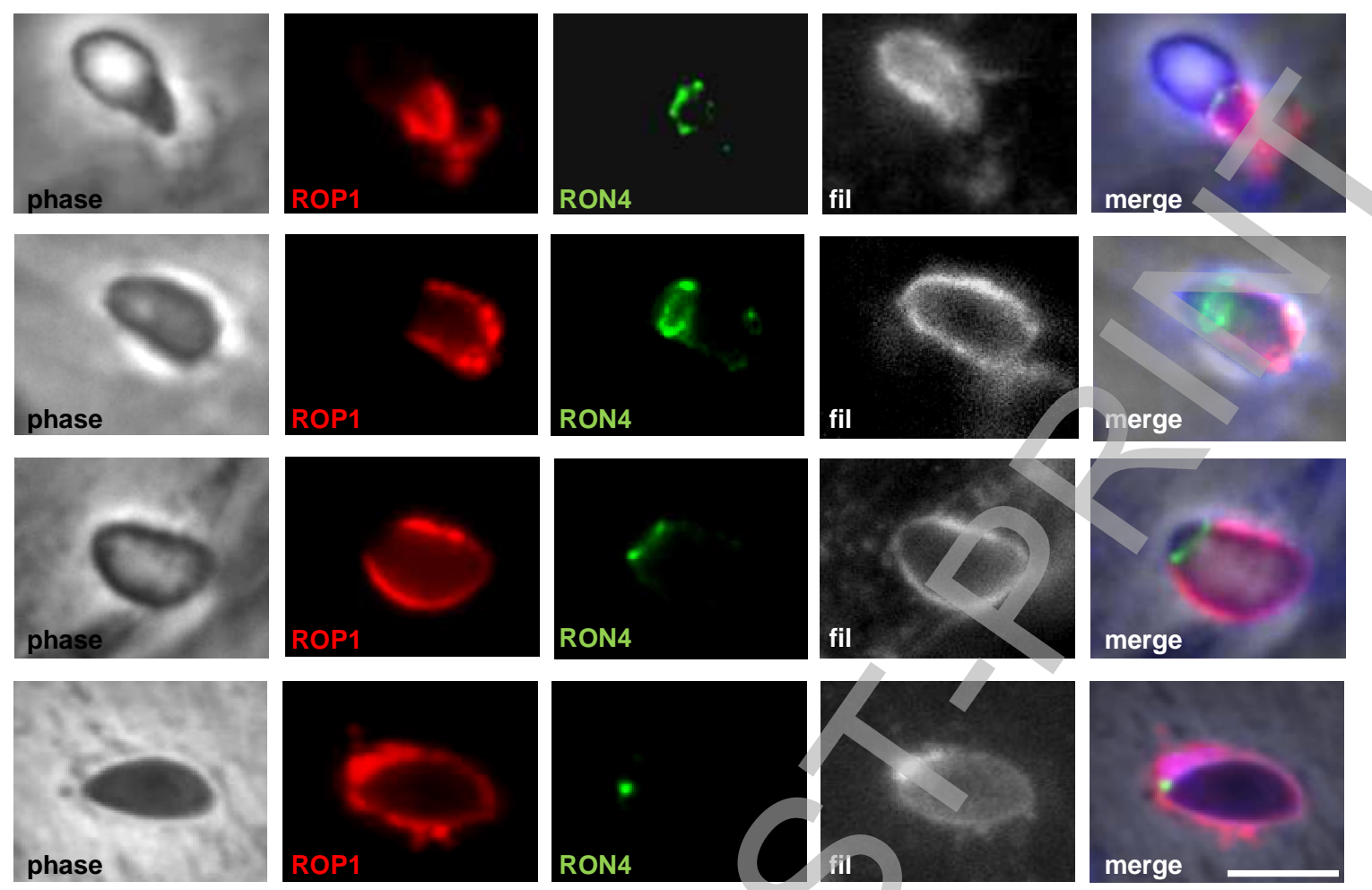

Figure 7.

$$
\text { - } 27 \text { - }
$$

Licenced copy. Copying is not permitted, except with prior permission and as allowed by law. ' 2008 The Authors Journal compilation ' 2008 Biochemical Society 